\title{
Screening of Oropharyngeal Dysphagia in Patients with Diabetes Mellitus in El- Demerdash Hospital (P-0919)
}

Meram M. Bekhet ${ }^{1}$, Marwa M. Saleh², Mona S. Khodeir ${ }^{2}$, Donia A. Zakaria ${ }^{2}$

${ }^{1}$ Ain-shams University Hospitals, diabetes- Endocrinology and metabolism department, Cairo, Egypt.

${ }^{2}$ Ain Shams University, ENT Department- Phoniatric Unit, Cairo, Egypt.

\section{Background}

Diabetes mellitus is a systemic endocrinal disease that results either from deficiency of insulin hormone (type 1) or from insulin resistance or both (type 2) [1]. Dysphagia is the medical term that is used to describe the difficulty of swallowing and the feeling of difficulty in passage of solids or semisolids or liquids from the mouth to the stomach [2-3].The pathophysiology of the oropharyngeal dysphagia in diabetics is still not completely clear. However, the autonomic neuropathy associated with long term hyperglycemia is claimed to be the cause [4]. Literature has hardly related to dysphagia with diabetes. This complaint is expressed by some patients and needs to be explored.

\section{Aim}

The aim of this work is to screen Egyptian diabetic patients (type 1 and type 2) in El-Demerdash hospital for oropharyngeal dysphagia using the validated Arabic version of Eating Assessment Tool (A-EAT-10) questionnaire in order to explore the degree of such symptom among them.

\section{Methods}

This was a cross sectional study conducted to screen the diabetic patients (of both type 1 and type 2) in El-Demerdash hospital for oropharyngeal dysphagia. 200 Egyptian adult diabetic patients, aged $18-59$ years, were included in this study. The present study included 118 patients of type 1 diabetes and 82 patients of type 2 diabetes. The participants were selected from Ain Shams university outpatient clinic. The inclusion and exclusion criteria were determined by the medical history taken from the patients before answering the Arabic version of Eating Assessment Tool (A-EAT-10) questionnaire [5].

Scoring of the A-EAT-10 questionnaire:

A patient with A-EAT-10 score equal to and/or more than 3 is considered dysphagic while patients with score of 2 or less are considered non-dysphagic and may need to be assessed by further tools.

\section{Exclusion criteria:}

Patients with any past or present history of one of the following disorders that might cause oropharyngeal dysphagia were excluded as:

- Thyroid disorders: enlargement, inflammation and tumors.

- Any neurological disorders.

- Head and neck trauma, cancer or radiation.

A systemic disease that might cause dysphagia

\section{Results}

The increase in mean age of the dysphagic patients (43.63 \pm 10.47$)$ years compared with the mean age of the non-dysphagic patients $(38.36 \pm 12.55)$ years with $\mathrm{p}=0.012$ and having a female gender $(22.6 \%$ of the female patients participating in this study complained from dysphagia symptoms compared to only $7.5 \%$ of the participating male patients, $P=0.008$ ) were considered of high risk for dysphagia among diabetic patients participating in this study. $23.2 \%$ of patients with diabetes mellitus type 2 had dysphagia symptoms compared to $13.6 \%$ of patients with diabetes mellitus type 1 who had dysphagia and this difference was statistically of no significance, $p=0.578$. There was no statistically significant difference between the dysphagic and non-dysphagic patients as regard the mean duration of the diabetes mellitus [Table 1]. The commonest symptom among diabetic patients who complained from dysphagia was "I cough when I eat".

Table [1]: Comparison between dysphagic and non-dysphagic patients as the mean age and gender (using chi-square tests) and mean duration and type of the diabetes mellitus (using student t-test). $P>0.05$ : Non-significant (NS), $P<0.05$ : Significant (S), $\mathrm{P}<0.01$ : Highly significant (HS)

\begin{tabular}{|c|c|c|c|c|c|}
\hline \multirow{2}{*}{\multicolumn{2}{|c|}{ Age mean ( $\pm S D)$}} & Non-dysphagic & Dysphagic & P-value & Sig. \\
\hline & & $38.36( \pm 12.55)$ & $43.63( \pm 10.47)$ & 0.012 & S \\
\hline \multirow{2}{*}{ Gender } & $\begin{array}{l}\text { No. of males } \\
(\%)\end{array}$ & $62(92.5 \%)$ & $5(7.5 \%)$ & \multirow{2}{*}{0.008} & \multirow{2}{*}{ HS } \\
\hline & $\begin{array}{l}\text { No. of females } \\
\text { (\%) }\end{array}$ & $103(77.4 \%)$ & $30(22.6 \%)$ & & \\
\hline \multirow{2}{*}{ Type of DM } & Type 1 (no. \%) & $102(86.4 \%)$ & $16(13.6 \%)$ & \multirow{2}{*}{0.578} & \multirow{2}{*}{ NS } \\
\hline & Type 2 (no. \%) & $63(76.8 \%)$ & $19(23.2 \%)$ & & \\
\hline \multicolumn{2}{|c|}{ Mean duration of DM $( \pm S D)$} & $12.84( \pm 8.65)$ & $11.94( \pm 9.22)$ & 0.584 & NS \\
\hline
\end{tabular}

\section{Conclusion}

Diabetic patients might encounter swallowing problems which could be overlooked by caregivers and should be put in consideration while dealing with diabetic patients. The A-EAT 10 is an easy method that can be used for screening of swallowing difficulty.

\section{References}

Dattani MT, Gevers EF. Endocrinology of fetal development. In: Williams Textbook of Endocrinology, 13th ed 2016; Philadelphia: Elsevier, chapter 32.

Smithard DG, Smeeton NC and Wolfe CD. Long-term outcome after stroke: does dysphagia matter. Age Ageing Journal, 2007; 36 (1): 90-4

Brady A. Managing the patient with dysphagia. Home Healthcare Nurse Journal, 2008; 26 (1): 41-6. . oropharat M, Mesallam TA. Validation and cultural adaptation of the Arabic version of the Eating Ass-2653. Tool (EAT-10). Folia Phoniatrica et Logopedica, 2015; 67:231-237. 